\title{
Factors affecting prepubertal growth in homozygous sickle cell disease
}

\author{
Atul Singhal, Joanne Morris, Peter Thomas, George Dover, Douglas Higgs, \\ Graham Serjeant
}

Medical Research Council Laboratories (Jamaica), University of the West Indies, Kingston, Jamaica A Singhal J Morris

P Thomas

G Serjeant

Department of Pediatric Hematology, Johns Hopkins Hospital, Baltimore, USA

G Dover

Medical Research Council Molecular Haematology Unit, Institute of Molecular Medicine, Oxford D Higgs

Correspondence and requests for reprints to: $\mathrm{Dr}$ Atul Singhal, Flat 2, 121 Chetwynd Road, London NW5 IDA.

Accepted 19 February 1996

\begin{abstract}
Objective-To investigate the role of haematological indices, socioeconomic status, and morbidity in prepubertal growth in homozygous sickle cell (SS) disease.

Method - Height, weight, and haematology were serially recorded in a cohort study of 315 children with SS disease from birth to 9 years at the sickle cell clinic of the University Hospital of the West Indies, Kingston, Jamaica.

Results- Height increment between 3 and 9 years correlated positively with total haemoglobin at age 7 years in boys but not girls. Attained height and weight at age 7 years correlated positively with haemoglobin and fetal haemoglobin in boys but not girls. Only the correlation between haemoglobin and weight showed a significant gender difference. Partial correlation analysis suggested that the effect of haemoglobin was accounted for by the effect of fetal haemolglobin and further analysis indicated that height correlated with $F$ reticulocyte count (a measure of fetal haemoglobin production) in both sexes but not with the ratio of $F$ cells to $F$ reticulocytes (a measure of $F$ cell enrichment). Growth was not significantly related to mean red cell volume, proportional reticulocyte count, $\alpha$ thalassaemia, socioeconomic status, or morbidity.
\end{abstract}

Conclusion-A high concentration of fetal haemoglobin in boys with SS disease is associated with greater linear growth. It is postulated that in boys, low concentrations of fetal haemoglobin increase haemolysis and hence metabolic requirements for erythropoiesis, putting them at greater risk of poor growth. Differences in the relationship of haematology and growth between boys and girls with SS disease dictate that future analyses of growth take gender into account. (Arch Dis Child 1996;74:502-506)

Keywords: prepubertal growth, sickle cell disease, fetal haemoglobin.

Prepubertal growth in homozygous sickle cell (SS) disease is generally slower than normal ${ }^{12}$ but the mechanisms of this retardation are unknown. The Jamaican cohort study of sickle cell disease has provided a representative sample of over 300 children with SS disease observed prospectively from birth and now all aged over 10 years. The growth of these children over the first 9 years has been assessed in relation to haematological indices, socioeconomic status, and clinical course to search for possible influences on growth in children with SS disease.

\section{Methods}

STUDY POPULATION

The patients attended the sickle cell clinic at the University Hospital of the West Indies and participated in a cohort study which included all cases with sickle cell disease detected among 100000 consecutive, non-operative deliveries at the main government maternity hospital between June 1973 and December 1981. The present report is confined to SS children with observations on growth for at least the first seven years. Of the 315 SS children detected, four failed to be recruited to the study, one defaulted at 11 days, 47 died, and four emigrated before their 7 th birthday. A further 18 (16 with cerebrovascular accidents, one with mental retardation, and one with systemic lupus erythematosis) were excluded because other factors may have influenced growth. The final study group included 241 children, although data in all children were not available for all analyses. The diagnostic techniques and methods of follow up have been described. ${ }^{34}$

\section{GROWTH}

Heights and weights were measured at three month intervals coinciding with birthdays by methods described elsewhere. ${ }^{5}$ The selected indices of growth were the attained height, weight, weight/height, and weight/height ${ }^{2}$ and their relationship with haematology was analysed at ages 3, 5, and 7 years, although only the more complete data available at 7 years are presented. Prepubertal growth was also depicted as the increment in height between 3-9 years, an age range selected because of the less reliable growth measurements and the more rapid age related changes in steady state haematology before age 3 years and the confounding effects of the pubertal growth spurt after age 9 years. Computer generated curves for height against age were used to identify and appropriately edit outlying values, which were usually due to transposition of figures. No explanation could be found for aberrant height values in $173(0.6 \%)$ of approximately 27000 observations so these were excluded from the analysis. The contribution of parental height to linear growth in SS disease could not be assessed as protocols did 
Table 1 Distributions of some indices in SS disease at age 7 years

\begin{tabular}{|c|c|c|c|c|c|}
\hline & \multicolumn{2}{|l|}{ Boys } & \multicolumn{2}{|l|}{ Girls } & \multirow{2}{*}{$\begin{array}{l}\text { Significance } \\
\text { p (value) } t\end{array}$} \\
\hline & No & Median (range) & No & Median (range) & \\
\hline Height $(\mathrm{cm})$ & 113 & $117.0(104.5-127.4)$ & 106 & $117.9(106.7-131.3)$ & 0.39 \\
\hline Weight (kg) & 113 & $19.7(14.4-24.7)$ & 105 & $19.1(14.1-25.7)$ & 0.075 \\
\hline Weight/height $(\times 100)$ & 113 & $16.6(13.8-19.6)$ & 105 & $16.2(13.0-20.3)$ & 0.007 \\
\hline Weight/height ${ }^{2}(\times 100)$ & 113 & $14.1(12.1-16.2)$ & 105 & $13.9(11.6-16.0)$ & 0.0003 \\
\hline Haemoglobin $(\mathrm{g} / \mathrm{l})^{\star}$ & 93 & $74(56-103)$ & 80 & $80(57-106)$ & 0.006 \\
\hline Haemolysate fetal haemoglobin $(\%)^{\star}$ & 71 & $5.9(0.3-26.2)$ & 65 & $6.1(0.9-21.0)$ & 0.48 \\
\hline Socioeconomic score & 92 & $12.0(2-18)$ & 91 & $11.0(1-18)$ & 0.12 \\
\hline
\end{tabular}

* Haematology at nearest steady state visit but within six months of 7 th birthday.

+ Significance by Mann-Whitney U test.

not collect data on parental height and this would have been very incomplete because of the high frequency of single parent or adopted families.

\section{HAEMATOLOGY}

Venepuncture blood samples were taken every six months or more often if clinically indicated. Haematological indices, including total haemoglobin and mean cell volume, were measured on a Coulter S plus 4 (Coulter Electronics) and reticulocyte counts by standard microscopic methods. Fetal haemoglobin was determined annually by alkali denaturation ${ }^{6}$ and $F$ cells and $F$ reticulocyte counts as described by Dover et $a l^{7}$ in a subgroup of steady state patients. The number of $\alpha$ globin genes was determined in 232 children available to the study after 1976. Only haematological indices taken during visits when the children were clinically well, excluding values for three months after a blood transfusion, were used in analyses.

\section{MORBIDITY}

Disease severity was assessed as the number of specific clinical events (hospital admissions, sickle cell clinic visits, painful crises, and episodes of acute chest syndrome, acute splenic sequestration, or hypersplenism) before the age of 7 years. The arbitrary nature of this assessment is recognised but no single index was ideal, and it was felt that the combination of indices gave a better approximation of overall morbidity. Furthermore these data were reasonably accurate and complete as patients had relied almost exclusively on the sickle cell clinic for their medical care from birth.

Morbidity data were collected by recording all clinical events at each clinic visit with recall of events between visits. The painful crisis was defined as bone pain severe enough to limit activity, acute chest syndrome as a history of cough and fever with clinical and/or radiological evidence of pulmonary consolidation, and acute splenic sequestration (ASS) and hypersplenism as previously described. ${ }^{8}$ In the analyses, all episodes of a clinical event occurring within seven days were assumed to represent a single event. The distribution of number of events up to the 7th birthday was grouped into approximate quartiles: painful crises 0 $(n=97), 1 \quad(n=58), 2-4 \quad(n=58), \geqslant 5 \quad(n=28)$; hospital admissions $0(n=71), 1 \quad(n=61), 2-3$ $(n=68), \geqslant 4 \quad(n=41)$; sick visits $0-7 \quad(n=57)$, 8-12 ( $n=61), 13-18 \quad(n=61), \geqslant 19 \quad(n=62)$; acute chest syndrome $0(n=75), 1(n=61), 2-3$ $(n=60), \geqslant 4(n=45)$. Episodes of ASS were categorised as $0(n=175), 1(n=33)$, and $\geqslant 2$ $(n=33)$ events.

\section{SOCIOECONOMIC STATUS}

The socioeconomic status of patients was assessed at age 8 years by a scoring system previously used in Jamaica, ${ }^{9}$ which recorded the number and types of household appliances, source of water, and type of sanitation. Paternal income as an indicator of socioeconomic status is inappropriate in Jamaica because of the high frequency of single parent families. Scores ranged from 1 (worst score) to 18.

\section{STATISTICAL ANALYSIS}

Statistical associations between growth, haematological indices, and socioeconomic status were initially examined by correlation coefficient analysis and, when appropriate, by partial correlation analysis to control for potential confounders. Comparisons of growth between morbidity groups and between sexes were assessed by analysis of variance. The distributions of total fetal haemoglobin, reticulocytes, $F$ cells, and $F$ reticulocytes were skewed and were transformed [ $\log _{10}$ (fetal haemoglobin +1 ), $\log _{10}$ (reticulocytes), $\log _{10} \mathrm{~F}$ reticulocytes, and $\log _{10}$ (F cells/F reticulocytes)] for parametric analysis.

\section{Results}

GENDER DIFFERENCES

At age 7 years, there were no significant sex differences in height, weight, socioeconomic score (table 1), or the frequency of any of the five indices of morbidity. There was no gender difference in steady state fetal haemoglobin concentration in this age group or in the number of subjects (six boys, one girl) with fetal haemoglobin below $1.0 \% \quad(p=0.15$ using Fisher's exact test). Weight/height and weight/ height ${ }^{2}$ were greater in boys and steady state fetal haemoglobin concentrations higher in girls.

GROWTH AND HAEMATOLOGY

Heights and weights at 3,5 , and 7 years correlated with steady state fetal haemoglobin in boys but not girls (results at 7 years are shown in table 2). Scatter plots of height against fetal haemoglobin did not support the notion of a 'cut off' level at which high fetal haemoglobin has a protective effect on height. Fetal haemoglobin correlated with weight/height and weight/height ${ }^{2}$ in boys at age 7 years, and 
Table 2 Relationship of some growth indices at 7 years with steady state total haemoglobin and fetal haemoglobin $(\mathrm{HbF})$

\begin{tabular}{|c|c|c|c|c|}
\hline & Height & Weight & Weight/height & Weight/height $t^{2}$ \\
\hline \multicolumn{5}{|l|}{ Boys } \\
\hline \multicolumn{5}{|c|}{ Haemoglobin } \\
\hline$r$ & 0.30 & $0.36^{\star}$ & $0.35^{\star}$ & $0.25^{\star}$ \\
\hline No & 88 & 88 & 88 & 88 \\
\hline p Value & 0.005 & $<0.001$ & 0.001 & 0.02 \\
\hline \multicolumn{5}{|c|}{$\log _{10}(H b F+1)$} \\
\hline$r$ & 0.34 & 0.40 & 0.38 & 0.25 \\
\hline No & 68 & 68 & 68 & 68 \\
\hline $\mathrm{p}$ Value & 0.005 & $<0.001$ & 0.002 & 0.043 \\
\hline \multicolumn{5}{|l|}{ Girls } \\
\hline \multicolumn{5}{|c|}{ Haemoglobin } \\
\hline$r$ & 0.03 & $-0.02^{\star}$ & $-0.04^{\star}$ & $-0.06^{\star}$ \\
\hline No & 76 & 75 & 75 & 75 \\
\hline $\mathrm{p}$ Value & 0.80 & 0.86 & 0.74 & 0.62 \\
\hline \multicolumn{5}{|c|}{$\log _{10}(H b F+1)$} \\
\hline$r$ & 0.18 & 0.21 & 0.17 & 0.06 \\
\hline No & 62 & 61 & 61 & 61 \\
\hline p Value & 0.16 & 0.10 & 0.18 & 0.67 \\
\hline
\end{tabular}

^ Significant gender differences in correlation coefficients ( $r$ ) (see text).

weight/height in boys at age 3 , but not in girls at any age. Height, weight, weight/height, and weight/height ${ }^{2}$ correlated with haemoglobin concentration in boys at 5 and 7 years of age but not at 3 years, and not at any age in girls (data for 7 years in table 2). Gender differences in the correlation coefficients existed for the relationships between haemoglobin and weight and weight/height but not for any of the other correlations in table 2.

The increment in height from 3-9 years correlated significantly with steady state haemoglobin at age 7 years $(r=0.33, p=0.006)$ and almost with fetal haemoglobin $(r=0.27$, $\mathrm{p}=0.056)$ in boys but not girls $(r=0.01, \mathrm{p}=0.94$ and $r=0.20, p=0.17$ respectively). In boys, partial correlation analysis of height and weight at 7 years on haemoglobin and fetal haemoglobin concentrations suggested that fetal haemoglobin accounted for the effects of haemoglobin as the latter was no longer significant after controlling for fetal haemoglobin. For weight/ height, weight/height ${ }^{2}$, and height increment it was not possible to identify the more important variable as associations with both haemoglobin and fetal haemoglobin became not significant after controlling for the other.

Attained height at 7 years correlated significantly with the percentage of $F$ cells and $F$ reticulocytes (table 3 ) in boys and that for $F$ reticulocytes just failed to reach significance for girls. The ratio of $F$ cells to $F$ reticulocytes (a measure of $F$ cell enrichment ${ }^{10}$ ) was not significantly related to height at 7 years in either sex. There were no significant gender differences in the correlations. No significant relationships were apparent between attained height or height increment and mean cell volume, reticulocyte count, or number of $\alpha$ globin genes in either sex (results not given).

GROWTH AND SOCIOECONOMIC STATUS

Socioeconomic scores did not correlate with any growth index at 7 years or with height increment from 3-9 years in either sex (correlations between -0.11 and 0.20 ).

GROWTH AND MORBIDITY

Neither height nor weight at 7 years was related to the number of hospital admissions, but haemoglobin and fetal haemoglobin both tended to decrease with the number of hospital visits in both sexes (table 4). There were no significant relationships of height, weight, or haemoglobin with the number of sick visits, episodes of acute chest syndrome, acute splenic sequestration, or hypersplenism apart from lower mean weights in females with few sick visits $(p=0.02)$. In males, a lower average fetal haemoglobin was associated with frequent sick visits $(p=0.02)$, hypersplenism $(p=0.003)$, and frequent painful crises $(p=0.003)$. In females, frequent painful crises were associated with higher mean haemoglobin $(p=0.04)$. There were no significant gender differences in the relationships between morbidity, and growth, and haematology except for the gender differences of haemoglobin and fetal haemoglobin with frequency of painful crises.

\section{MISSING DATA}

The growth of $47 / 315$ patients with SS disease who died before 7 years was assessed by calculating standardised scores (z scores) for height (relative to the growth of the whole cohort) at the age of their last assessment. The mean

Table 3 Relationship of attained height at 7 years with $F$ cells, $F$ reticulocytes, and $F$ cell/F reticulocyte ratio

\begin{tabular}{lccc}
\hline & $F$ cells & $\begin{array}{l}\log _{10} \\
\left(F_{\text {reticulocytes })}\right)\end{array}$ & $\begin{array}{l}\log _{10}\left(F_{\text {cells }}\right. \\
\text { F reticulocytes })\end{array}$ \\
\hline Boys & & & \\
$r$ & 0.44 & 0.46 & -0.23 \\
No & 38 & 40 & 38 \\
p Value & 0.006 & 0.003 & 0.16 \\
Girls & & & -0.33 \\
$r$ & 0.17 & 0.39 & 26 \\
No & 26 & 26 & 0.10 \\
p Value & 0.42 & 0.05 &
\end{tabular}

Table 4 Relationship between hospital admissions, growth, and haematology; values are mean (SD) except for fetal haemoglobin which is median (range)

\begin{tabular}{|c|c|c|c|c|c|}
\hline & \multicolumn{4}{|c|}{ No of hospital admissions } & \multirow{2}{*}{$\begin{array}{l}\text { Analysis of } \\
\text { variance } \\
\text { (p value) }\end{array}$} \\
\hline & 0 & 1 & 2,3 & $4+$ & \\
\hline \multicolumn{6}{|c|}{ Height (cm) } \\
\hline $\mathrm{F}$ & $119.1(4.6)$ & $116.7(4.8)$ & $116.2(5.2)$ & $119.0(5.5)$ & 0.06 \\
\hline $\mathbf{M}$ & $117.6(5.6)$ & $116.9(4.2)$ & $117.4(5.5)$ & $116.3(4.2)$ & 0.82 \\
\hline \multicolumn{6}{|c|}{ Weight (kg) } \\
\hline $\mathrm{F}$ & $19.6(2.3)$ & $18.6(2.1)$ & $18.5(1.5)$ & $19.5(1.9)$ & 0.08 \\
\hline $\mathbf{M}$ & $19.7(2.2)$ & $19.7(2.4)$ & $19.6(2.4)$ & $19.1(1.4)$ & 0.83 \\
\hline \multicolumn{6}{|c|}{ Haemoglobin $(\mathrm{g} / \mathrm{l})$} \\
\hline $\mathbf{F}$ & 84 (12) & $80 \quad(8)$ & $76 \quad(9)$ & $76 \quad(11)$ & 0.03 \\
\hline $\mathbf{M}$ & 82 (11) & 76 (10) & 72 (11) & $71 \quad(10)$ & 0.005 \\
\hline \multicolumn{6}{|c|}{ Fetal haemoglobin (\%) } \\
\hline F & $8.0(2.9-16.7)$ & $8.0(2.4-21.0)$ & $4.8(1.0-10.6)$ & $3.8(0.9-8.0)$ & 0.0005 \\
\hline $\mathbf{M}$ & $7.6(0.7-26.2)$ & $6.6(1.1-19.3)$ & $3.3(0.3-18.3)$ & $3.3(0.5-12.6)$ & 0.03 \\
\hline
\end{tabular}


(SD) $\mathrm{z}$ score of patients that had died, -0.24 (1.34), was not significantly different from zero, suggesting that the growth of children remaining in the study at age 7 years was representative of growth in those diagnosed at birth.

Of the 241 children theoretically eligible for the analysis at age 7 years, values at 7 years \pm 3 months were not available for height in 22 $(9 \%)$, for steady state haemoglobin in 68 $(28 \%)$, and for steady state fetal haemoglobin concentrations in 105 (44\%). However steady state haemoglobin and fetal haemoglobin (calculated from the mean of all steady state values from age 5 years) did not differ substantially in patients with and without steady state data at age 7 years and all differences were not significant suggesting that bias was not introduced by exclusion of these subjects. Furthermore the mean heights of patients with or without steady state fetal haemoglobin and haemoglobin concentrations at age 7 years were similar, although there was a trend for patients with steady state haemoglobin and fetal haemoglobin concentrations at age 7 years to be approximately $0.7 \mathrm{~kg}$ heavier than those without such data. The height, haemoglobin, and fetal haemoglobin concentrations (at age 7 years) of the subset of patients with $F$ cell data did not differ from subjects without such data.

\section{Discussion}

Growth is a complex process influenced by genetic and environmental factors and abnormal growth secondary to chronic disease may have many different aetiologies. Homozygous sickle cell (SS) disease is generally associated with altered growth, low body weight and retarded height velocity being particularly characteristic, but the causal factors are unknown. Anaemia, recurrent infections, and other aspects of chronic ill health are assumed to contribute but there is a dearth of data. The present study has analysed several indices of growth between 3-9 years and found significant relationships with haemoglobin and fetal haemoglobin concentrations both of which showed interesting gender differences, but no contributions from indices of morbidity or socioeconomic status.

The lack of effect from socioeconomic status was surprising as low socioeconomic status is well established as a cause of poor growth. This may reflect the relatively imprecise nature of the socioeconomic scoring employed in the present study which documented water supply and sewage services but leant heavily on provision of services such as electricity, telephone, and appliance use. This is known to underestimate the socioeconomic status of people in rural areas where nutrition may be excellent but electricity and telephone services unavailable. The social structure of many Jamaican families does not allow the use of paternal income as a reliable indicator and even maternal income may be erratic and inconsistent. It seems likely that the lack of an apparent effect of socioeconomic status may be attributable to a relatively insensitive indicator of socioeconomic status in this community.
Parental height, another important determinant of height, was not recorded in the initial protocols and would have been relatively incomplete because of the high frequency of one parent families.

The lack of association between growth and the selected indices of morbidity was surprising and is open to several interpretations. It is possible that indices such as painful crises, acute chest syndrome, and acute splenic sequestration are of too short duration to affect growth or that faltering growth is obscured by catch up growth during asymptomatic periods. It is also possible that more common, minor, recurrent episodes such as gastroenteritis or upper respiratory tract infections have a greater impact on growth, although this would have been expected to be reflected in a greater prevalence of sick visits to the clinic.

The relationships between haematology and growth provided some new, potentially important observations. Growth was not related to haemolytic rate as assessed by reticulocyte count, which was of interest as the impaired growth in hypersplenic SS children and the growth spurt following splenectomy in such cases ${ }^{11}$ had been interpreted as the impact of a markedly expanded bone marrow competing with the requirements of the growth plates for normal growth. Since a high reticulocyte count correlates with red cell survival and other indices of bone marrow expansion, ${ }^{12}$ the lack of a relationship calls for this hypothesis to be reassessed. There was also no relationship between growth and mean cell volume or $\alpha$ thalassaemia status. $\alpha$ Thalassaemia reduces the intracellular concentration of sickle cell haemoglobin and the degree of intravascular sickling and so might be expected to be associated with less bone marrow expansion and less vaso-occlusion, both potential determinants of abnormal growth.

The relationships of growth with haemoglobin and fetal haemoglobin showed potentially interesting gender differences, high haemoglobin and fetal haemoglobin concentrations being related to attained height and weight at 5 and 7 years and to height increment from 3-9 years in boys but not in girls. Gender differences were only significant for the relationship between haemoglobin and weight and weight/height. Further analysis suggested that the apparent effect of total haemoglobin on height and weight was mediated through an effect of fetal haemoglobin.

The uneven intracellular distribution of fetal haemoglobin in SS disease implies that red cells may contain variable amounts of fetal haemoglobin, cells with low fetal haemoglobin concentrations being more prone to sickling and earlier removal from the circulation. Cells with high fetal haemoglobin persist for longer and this cell selection increases the concentration of fetal haemoglobin. Raised fetal haemoglobin may result from increased production (measured by $F$ reticulocyte counts ${ }^{10}$ ) or cell selection (measured by the $F$ cell to $F$ reticulocyte ratio ${ }^{10}$ ) without increased production. As these two mechanisms have different implications, further examination of this relationship 
showed that only the $\mathrm{F}$ reticulocyte count and not the $F$ cell to $F$ reticulocyte ratio was related to the height at 7 years. Even in females where no significant relationship between growth and haemolysate fetal haemoglobin or F cells was apparent, the relationship with $\mathrm{F}$ reticulocyte count reached significance. As the $F$ reticulocyte count in SS disease is characteristic of an individual ${ }^{10}$ these observations suggest that the individual level of fetal haemoglobin production is the factor related to better growth. Possible mechanisms whereby high fetal haemoglobin concentrations influence growth include a reduction in erythropoietic activity tending to reduce the competition of erythropoiesis for amino acids and calories essential for growth or the greater general clinical severity in patients with low fetal haemoglobin, ${ }^{13}$ neither possibility receiving support from the present study.

A possible gender difference in the effect of fetal haemoglobin on growth may serve to explain several earlier observations. The protective effects of fetal haemoglobin on age at first occurrence of painful crises, ASS and dactylitis, ${ }^{13}$ abnormal body habitus, ${ }^{14}$ skeletal retardation, ${ }^{15}$ proliferative sickle retinopathy, ${ }^{16}$ and avascular necrosis of the femoral head ${ }^{17}$ have all been confined to males. Genotype differences in anthropometric indices and in nutrient intake were also confined to males in a Nigerian study. ${ }^{18}$ A possible mechanism of this sex related effect, that the relationship is created by males with very low fetal haemoglobin concentrations, ${ }^{13}$ was not supported in this study. Another possibility is that a low fetal haemoglobin concentration accentuates a gender related difference in erythropoietic and metabolic activity that is already present but of unknown mechanism, a hypothesis supported by the greater resting metabolic rate, ${ }^{19}$ irreversibly sickled cell counts (a determinant of haemolysis), ${ }^{20}$ serum transferrin receptor levels (a measure of erythropoietic activity), ${ }^{21}$ and poorer growth in males. ${ }^{22}$ A higher fetal haemoglobin may reduce the metabolic demands of bone marrow so protecting against avascular complications and poor growth in boys. Future analyses of morbidity and haematological indices and of treatments that aim to increase fetal haemoglobin should recognise that these relationships may differ between males and females.

1 Stevens MCG, Maude GH, Cupidore L, et al. Prepubertal growth and skeletal maturation in children with sickle cell disease. Pediatrics 1986; 78: 124-32.

2 Platt OS, Rosentock W, Espeland MA. Influence of sickle hemoglobinopathies on growth and development. $\mathrm{NEngl} f$ Med 1984; 311: 7-12.

3 Stevens MCG, Hayes RJ, Vaidya S, et al. Fetal hemoglobin and clinical severity of homozygous sickle cell disease in early childhood. F Pediatr 1981; 98: 37-41.

4 Serjeant BE, Forbes M, Williams LL, et al. Screening cord bloods for the detection of sickle cell disease in Jamaica. Clin Chem 1974; 20: 666-9.

5 Singhal A, Thomas P, Cook R, et al. Delayed adolescent growth in homozygous sickle cell disease. Arch Dis Child 1994; 71: 404-8.

6 Betke K, Marti HR, Schlicht I. Estimation of small percentages of foetal haemoglobin. Nature $1959 ; 184: 1877-8$.

7 Dover GJ, Boyer SH, Bell WR. A microscopic method for assaying $\mathrm{F}$ cell production: illustrative changes during assaying $F$ cell production: illustrative changes during
infancy and in aplastic anemia. Blood $1978 ; 52: 664-72$.

8 Topley JM, Rogers DW, Stevens MCG, Serjeant GR. Acute pley JM, Rogers DW, Stevens MCG, Serjeant GR. Acute
splenic sequestration and hypersplenism in the first five splenic sequestration and hypersplenism in the first five
years in homozygous sickle cell disease. Arch Dis Child years in homozy 1981 ; 56: 765-9.

9 Alleyne SI, Morrison YSA, Richards RR. Some social factors related to control of diabetes in adult Jamaican patients. Diabetes Care 1979; 2: 401-8.

10 Dover GJ, Boyer SH, Charache S, et al. Individual variation in the production and survival of F-cells in sickle-cell disease. N Engl f Med 1978; 299: 1428-35.

11 Singhal A, Thomas P, Kearney T, Venugopal S, Serjeant G. Acceleration in linear growth after splenectomy for hypersplenism in homozygous sickle cell disease. Arch Dis Child 1995; 72: 227-9.

12 Serjeant GR, Serjeant B, Stephens A, et al. Determinants of haemoglobin level in steady-state homozygous sickle cell disease. Br $\mathcal{F}$ Haematol 1996; 92:143-9.

13 Bailey K, Morris JS, Thomas P, Serjeant GR. Fetal haemoglobin and early manifestations of homozygous sickle cell globin and early manifestations of homozyg
disease. Arch Dis Child 1992; 67: 517-20.

14 Ashcroft MT, Serjeant GR. Body habitus of Jamaican adults with sickle cell anemia. South Med f 1972; 65: 579-82.

15 Serjeant GR, Ashcroft MT. Delayed skeletal maturation in sickle cell anemia in Jamaica. fohns Hopkins Med f 1973; 132: 95-102.

16 Hayes RJ, Condon PI, Serjeant GR. Haematological factors associated with proliferative retinopathy in homozygous sickle cell disease. Br f Ophthalmol 1981; 65: 29-35. 17 Hawker $\mathrm{H}$, Neilson $\mathrm{H}$, Hayes RJ, et al. Haematological facin homozygous sickle cell disease. Br 7 Haematol 1982; 50: 29-34.

18 Modebe O, Ifenu SA. Growth retardation in homozygous sickle cell disease: role of calorie intake and possible sickle cell disease: role of calorie intake and possible gender-rela

19 Singhal A, Davies P, Sahota A, et al. Resting metabolic rate in homozygous sickle cell disease. Am F Clin Nutr 1993; 57: $32-4$

20 Mason KP, Grandison Y, Hayes RJ, et al. Post-natal decline of fetal haemoglobin in homozygous sickle cell disease: relationship to parental $\mathrm{HbF}$ levels. Br $\mathcal{f}$ Haematol 1982; 52: 455-63.

21 Singhal A, Cook JD, Skikne BS, et al. The clinical significance of serum transferrin receptor levels in sickle cell disease. Br $\mathcal{F}$ Haematol 1993; 84: 301-4.

22 Phebus CK, Gloninger MF, Maciak BJ. Growth patterns by age and sex in children with sickle cell disease. $\mathcal{F}$ Pediatr 1984; 105: 28-33. 